\title{
Tantangan Digital dan Dinamisasi Koleksi dalam Pemanfaatan Koleksi Perpustakaan bagi Prestasi Belajar Mahasiswa
}

\author{
Sugeng Wahyuntini ${ }^{1}$, Sri Endarti ${ }^{2}$ \\ ${ }^{1,2}$ UPT Perpustakaan Institut Seni Indonesia Yogyakarta \\ Jalan Parangtritis km. 6,5 Yogyakarta \\ HP.: 081904003010; Email: sywahyu@gmail.com
}

\begin{abstract}
Abstrak
Tulisan ini merupakan artikel ilmiah dari penelitian berjudul "Intensitas Pemanfaatan Koleksi Perpustakaan bagi Prestasi Belajar Mahasiswa Fakultas Seni Pertunjukan ISI Yogyakarta”. Tujuan penelitian adalah: (1) Untuk mengetahui intensitas pemanfaatan koleksi perpustakaan oleh mahasiswa Fakultas Seni Pertunjukan ISI Yogyakarta; (2) Untuk mengetahui dampak intensitas pemanfaatan koleksi perpustakaan terhadap prestasi belajar mahasiswa Fakultas Seni Pertunjukan ISI Yogyakarta. Penelitian berfokus pada intensitas pemanfaatan koleksi perpustakaan oleh mahasiswa Fakultas Seni Pertunjukan ISI Yogyakarta yang sudah dalam masa menjelang akhir studi dan sering berkunjung ke perpustakaan. Penelitian ini dilaksanakan di UPT Perpustakaan ISI Yogyakarta dengan informan sejumlah 11 orang, yaitu 10 orang mahasiswa yang ditentukan berdasarkan prodinya dan satu dosen FSP yang sering berkunjung ke perpustakaan. Analisis data yang digunakan adalah analisis kualitatif yang dilakukan dengan menggunakan model Miles \& Hubermen. Hasil penelitian menunjukkan bahwa intensitas pemanfaatan koleksi perpustakaan meningkat di saat ada dorongan untuk menyelesaikan tugas yang diberikan oleh dosen maupun untuk menyelesaikan tugas akhir. Selain memanfaatkan koleksi dengan membaca, meminjam menyalin dan memfotokopi, mahasiswa sudah memanfaatkan koleksi repository institusi. Cara mengakses informasi tidak hanya secara fisik berkunjung ke perpustakaan tetapi juga mengakses secara digital di luar perpustakaan. Kendala yang ditemukan adalah kurang lengkapnya koleksi hingga ke subyek minat utama dan kurang lancarnya wifi untuk akses informasi digital. Sedangkan kendala untuk kunjungan fisik ke perpustakaan adalah ruangan yang tidak nyaman (panas). Prestasi belajar mahasiswa mengalami peningkatan pada saat mahasiswa aktif memanfaatkan koleksi perpustakaan.
\end{abstract}

Kata kunci: koleksi; prestasi belajar; mahasiswa

\begin{abstract}
Digital Challenges and The Dynamization of Collections in The Utilization of Library Collections for Student Learning Achievement. This paper is a scientific article from the research entitled "Intensity of Utilization of Library Collection for Student Learning Achievement of Faculty of Performing Arts ISI Yogyakarta". The purpose of the study is: (1) To find out the intensity of the utilization of library collections by students of the Faculty of Performing Arts ISI Yogyakarta; (2) To find out the impact of the intensity of the utilization of library collections on the learning achievement of students of the Faculty of Performing Arts ISI Yogyakarta. Research focuses on the intensity of the utilization of library collections by students of the Faculty of Performing Arts ISI Yogyakarta. They are already in the period towards the end of their studies and often visit the library. This research was conducted at UPT Library ISI Yogyakarta with informants of 11 people, namely 10 students who were determined based on their study programs and one FSP lecturer who often visited the library. The data analysis used is a qualitative analysis conducted using the Miles \& Huberman model. The results showed that the intensity of library collection utilization increased when there was a push to complete the task given by lecturers and to complete the final task. In addition to
\end{abstract}


utilizing collections by reading, borrowing copies and photocopying, students have being used the institution's repository collection. How to access information is not only physically visiting the library but also accessing digitally outside the library. The obstacles found are the incompleteness of collections to the main interest subjects and the lack of smooth wifi for access to digital information. In comparison, the impediment to a physical visit to the library is an uncomfortable room (hot). Student learning achievement has increased when students actively utilize library collections.

Keywords: collection; learning achievement; students

\section{A. Pendahuluan}

Saat ini informasi sudah mulai menjadi suatu kebutuhan primer masyarakat. Semua lapisan masyarakat membutuhkan informasi, demikian juga dengan civitas akademika serta staf/pegawai juga membutuhkan informasi. Pendidikan Tinggi adalah jenjang tertinggi pada jalur pendidikan persekolahan dengan tugas dan kewenangan untuk menyelenggarakan program pendidikan akademik dan profesional. Undang-Undang RI No. 43 Tahun 2007 tentang Perpustakaan menyebutkan "Ayat 1, setiap perguruan tinggi menyelenggarakan perpustakaan yang memenuhi standar nasional perpustakaan dengan memperhatikan Standar Nasional Pendidikan. Ayat 2, perpustakaan sebagaimana dimaksud pada ayat (1) memiliki koleksi, baik jumlah judul maupun jumlah eksemplarnya, yang mencukupi untuk mendukung pelaksanaan pendidikan, penelitian, dan pengabdian kepada masyarakat.

Pemanfaatan perpustakaan oleh mahasiswa sangat erat kaitannya dengan proses perkuliahan yang diselenggarakan oleh perguruan tinggi yang bersangkutan. Kedatangan mahasiswa ke perpustakaan juga disebabkan oleh adanya kebutuhan informasi yang mendorong mereka untuk memanfaatkan koleksi perpustakaan yang telah disediakan. Pemanfaatan koleksi yang dilakukan mahasiswa juga menggambarkan bahwa peran perpustakaan tetap menjadi bagian penting dan dibutuhkan. Kenyamanan ruang dan kelengkapan koleksi serta pelayanan yang diberikan oleh perpustakaan adalah syarat mutlak untuk meningkatkan kemauan dan kemampuan belajar mahasiswa yang akan mempengaruhi minat belajar dan berdampak terhadap prestasi belajarnya.
Proses belajar-mengajar merupakan suatu sistem yang tidak lepas darikomponen-komponen lain yang saling berinteraksi di dalamnya. Perpustakaan merupakan suatu fasilitas yang disediakan oleh lembaga untuk menunjang proses belajar-mengajar peserta didik sehingga perpustakaan harus dimanfaatkan seoptimal mungkin. Fungsi perpustakaan sebagai sumber belajar telah berkembang sedemikian rupa sehingga perpustakaan sekarang merupakan bagian dari apa yang dinamakan pusat sumber belajar. Di dalam pusat sumber belajar ini ada fungsifungsi yang lebih luas yaitu ada fungsi-fungsi yang sifatnya pelayanan bahan- bahan ajar yang telah tersedia, fungsi pelatihan, konsultasi, produksi, peralatan dan perawatan. Kriteria pusat sumber belajar adalah material yang ada harus tersedia dalam jumlah dan kualitas yang cukup, mudah diakses oleh pengguna dan harus relevan dengan program-program yang ditawarkan.

Karakteristik perguruan tinggi seni adalah adanya mata kuliah praktek yang harus ditempuh oleh para mahasiswa dengan ketrampilan yang terus ditingkatkan sesuai dengan kurikulum yang sudah ada. Semakin banyak dilatih maka akan semakin meningkat pula ketrampilan yang mereka miliki. Mahasiswa seni tidak hanya menggunakan mata dan telinga sebagai sarana belajar, namun menggunakan anggota tubuh lainnya untuk mengasah ketrampilan dalam olah seni. Pada semester-semester tertentu para mahasiswa lebih banyak terfokus pada latihan ketrampilan.

Perkembangan teknologi sangat mempengaruhi pengelolaan perpustakaan dalam menghimpun, mengorganisir dan mendistribusikan atau melayankan informasi yang ada kepada pemustaka. Untuk koleksi digital mahasiswa sudah 
mendapatkan informasi bagaimana memanfaatkan repository institusi, baik melalui pustakawan maupun dalam kegiatan pendidikan pemakai.

Pada semester genap tahun ajaran 2019/2020 mahasiswa Fakultas Seni Pertunjukan ISI Yogyakarta meluluskan program studi D4/S1 sebanyak 214 mahasiswa dengan 63 mahasiswa mendapatkan predikat cumlaude. Prestasi belajar mahasiswa yang dicapai selain ditentukan oleh kemampuan mahasiswa itu sendiri juga ditentukan oleh seringnya mahasiswa memanfaatkan perpustakaan sebagai sumber informasi ilmiah.

Berdasarkan observasi pendahuluan, kebanyakan mahasiswa Fakultas Seni Pertunjukan ISI Yogyakarta lebih banyak memanfaatkan koleksi perpustakaan dengan cara membaca dan meminjam buku untuk menyelesaikan tugas-tugas mata kuliah yang diberikan oleh dosen dan pada saat menyelesaikan tugas akhir. Buku praktek musik juga dimanfaatkan dengan cara dipinjam lalu difotokopi. Namun untuk koleksi terbitan berkala belum maksimal dimanfaatkan. Namun pada saat penelitian ini dilakukan, perpustakaan belum menyusun laporan rutin pemanfaatan koleksi digital yang telah diakses oleh para pemustaka.

Dengan kondisi tersebut maka penelitian ini dilakukan guna mengetahui bagaimana intensitas pemanfaatan koleksi perpustakaan oleh mahasiswa FSP ISI Yogyakarta yang sudah dalam masa akhir studi terhadap pentingnya memanfaatkan koleksi sumber belajar (perpustakaan) untuk prestasi belajar mereka.

\section{B. Metode Penelitian}

Penelitian ini dilaksanakan di UPT Perpustakaan ISI Yogyakarta pada bulan Juni 2020 sampai dengan bulan November 2020. Metode penelitian yang digunakan adalah penelitian kualitatif deskriptif. Metode penelitian kualitatif adalah metode penelitian yang berlandaskan pada filsafat postpositisme, digunakan untuk meneliti pada kondisi obyek alamiah, (sebagai lawannya adalah eksperimen) dimana peneliti adalah sebagai instrumen kunci, pengambilan sampel sumber data yang dilakukan secara purposive dan snowball, teknik pengumpulan dengan triangulasi (gabungan), analisis data bersifat induktif/kualitataif, dan hasil penelitian kualitatif lebih menekankan pada makna dari pada generalisasi (Sugiyono, 2015: 1).

Sumber data dibedakan menjadi:

\section{Data Primer}

Sumber data yang diperoleh langsung yang dalam hal ini data yang diperoleh dari para informan.

\section{Data Sekunder}

Dalam penelitian ini sumber data diperoleh dari literatur/pustaka/arsip dan dokumen operasional yang relevan dengan objek penelitian.

Jenis data yang dikumpulkan dalam penelitian ini adalah data kualitatif. Teknik pengumpulan data menggunakan:

\section{Observasi}

Observasi dilakukan dengan menggunakan teknik sistematis/berstruktur (dengan menggunakan pedoman sebagai instrumen pengamatan) karena peneliti telah mengetahui aspek atau aktivitas apa yang ingin diamati yang relevan dengan masalah dan tujuan penelitian.

2. Wawancara

Wawancara dilakukan dengan teknik struktur dan tidak terstruktur. Penentuan informan dilakukan dengan menggunakan teknik purposive sampling, yaitu pengambilan sampel yang dilakukan dengan mempertimbangkan faktor tertentu, yaitu orang yang dianggap paling mengerti tentng objek yang diteliti. Dalam penelitian ini ditentukan 10 mahasiswa (masing-masing mewakili prodi yang ditempuh) yang telah duduk di semester $\mathrm{V}$ ke atas dan 1 orang tenaga pengajar yang sering berkunjung ke perpustakaan.

\section{Dokumentasi}

Dokumen yang digunakan adalah buku panduan ISI Yogyakarta, perundang-undangan, peraturan perpustakaan, data KHS (Kartu Hasil Studi), dan dokumen operasional yang relevan dengan penelitian.

Yusuf (2015: 332) menyebutkan peneliti adalah instrumen kunci (key-instrument) dalam penelitian. Dalam penelitian ini yang menjadi instrumen utama adalah peneliti sendiri. Peneliti melakukan observasi, membuat catatan dan melakukan wawancara. 
Teknis pengumpulan data dalam penelitian ini langkah pertama yang dilakukan adalah dengan mengorganisir data dan setelah data lapangan terkumpul kemudian diolah dan dianalisis dengan menggunakan analisis studi kasus.

Analisis data kualitatif dilakukan dengan menggunakan model Miles dan Hubermen. Dalam model ini analisis data dilakukan dengan cara reduksi data, penyajian data dan penarikan kesimpulan atau verifikasi.

Dalam penelitian ini teknik pemeriksaan data dilakukan dengan triangulasi. Patton (Moleong, 2006: 330) menegaskan bahwa triangulasi adalah teknik pemeriksaan keabsahan data yang memanfaatkan sesuatu yang lain di luar data itu untuk keperluan pengecekan atau pembanding terhadap data itu.

\section{Hasil dan Pembahasan}

Belajar mengajar sebagai suatu proses merupakan suatu sistem yang tidak lepas dari komponen-komponen lain yang saling berinteraksi di dalamnya. Salah satu komponennya adalah sumber belajar, dan perpustakaan adalah salah satunya. Perpustakaan perguruan tinggi yang mampu menjalankan fungsinya dengan baik akan mampu menyediakan informasi yang dibutuhkan mahasiswa. Mahasiswa juga akan senang berhubungan dengan perpustakaan karena perpustakaan mampu memahami kebutuhannya. Berdasarkan teori-teori yang telah disebutkan di bab terdahulu menunjukkan bahwa frekuensi kunjungan, tujuan ke perpustakaan, jenis koleksi yang dimanfaatkan, cara memanfaatkan koleksi, kelengkapan koleksi, suasana dan fasilitas perpustakaan serta layanan yang diberikan oleh pustakawan merupakan indikator yang berhubungan dengan tingkat pemanfaatan perpustakaan. Sedangkan indikator prestasi belajar adalah nilai IPK (Indeks Prestasi Kumulatif).

Dalam penelitian ini dapat diketahui bahwa frekuensi kedatangan mahasiswa bergantung dengan kebutuhannya. Tujuan mahasiswa berkunjung ke perpustakaan dari hasil wawancara mayoritas informan bertujuan untuk mencari referensi dalam menyelesaikan tugas kuliah termasuk informasi untuk menyusun tugas akhir. Hal ini sesuai dengan pernyataan informan pembanding yang selalu menganjurkan kepada para mahasiswa untuk mencari informasi ke perpustakaan dalam menyelesaikan tugas-tugas kuliah yang diberikan. Dari keterangan yang diberikan oleh para informan dapat disimpulkan bahwa dalam menyelesaikan tugas-tugas kuliah (termasuk mata kuliah praktek) para mahasiswa tetap membutuhkan perpustakaan sebagai pusat informasi. Dari hasil wawancara juga didapatkan bahwa mereka yang menambahkan frekuensi ke perpustakaan untuk mencari referensi pribadi guna menambah pengetahuan dan ada yang memanfaatkannya sebagai sarana rekreasi.

Secara umum, koleksi perpustakaan terdiri dari bahan tercetak dan bahan non cetak. Dari hasil wawancara didapat data bahwa mahasiswa datang ke perpustakaan rata-rata untuk mencari informasi dalam bentuk tercetak. Koleksi yang paling sering dimanfaatkan adalah buku-buku yang dengan subyek yang sesuai dengan prodi yang mereka tempuh. Jurnal maupun majalah juga dimanfaatkan tetapi belum maksimal. Hanya satu informan yang menyatakan sering memanfaatkan majalah. Namun dari hasil wawancara juga diketahui bahwa ada tujuh informan yang sudah memanfaatkan repository institusi. Mahasiswa juga cukup familier dengan penggunaan OPAC Mobile untuk mencari koleksi yang mereka inginkan tanpa harus datang ke perpustakaan.

Mahasiswa datang ke perpustakaan untuk memanfaatkan koleksi dengan cara membaca, mencatat, memfotokopi dan meminjam. Dari hasil wawancara didapat data bahwa cara paling dominan dalam memanfaatkan koleksi perpustakaan adalah dengan membaca di tempat. Setelahnya sesuai urutan terbanyak adalah meminjam, mencatat/ menyalin dan memfotokopi. Selain itu untuk mendapatkan informasi dalam menyelesaikan tugas kuliah, ada satu informan yang memanfaatkan koleksi sebagai penyaluran hobi membaca.

Koleksi perpustakaan merupakan salah satu media yang dimanfaatkan oleh mahasiswa. Dari hasil wawancara diperoleh data bahwa dalam menilai kelengkapan koleksi rata-rata mahasiswa menyatakan cukup lengkap untuk kebutuhan mereka. Artinya, untuk kebutuhan menyelesaikan 
tugas kuliah, informasi yang ada di perpustakaan sudah memadai. Mereka menyatakan bahwa koleksi bidang seni sulit dicari di perpustakaan lain. Namun untuk kebutuhan informasi yang lebih spesifik yang berhubungan dengan minat utama, koleksi dirasa kurang lengkap dan ini dirasakan oleh mahasiswa yang sedang menyusun tugas akhir.

Mahasiswa akan tertarik berkunjung ke perpustakaan dengan suasana yang nyaman dan tenang sehingga pemanfaatan perpustakaan bisa maksimal agar dapat membantu mahasiswa dalam menyerap informasi yang dibutuhkan sehingga bisa mendukung pencapaian prestasi belajar mereka. Dari hasil wawancara diperoleh data bahwa ruang baca perpustakaan dirasa kurang nyaman karena panas, terutama untuk layanan Ruang Skripsi di lantai dua. Hal ini sesuai dengan observasi yang dilakukan sebelumnya. Ruang layanan skripsi memang belum menggunakan AC dan hanya menggunakan kipas angin yang tidak mencakup ke segala arah.

Layanan perpustakaan merupakan layanan yang mempertemukan langsung antara pustakawan dengan pemustakanya. Pemustaka menginginkan untuk mendapatkan layanan yang baik. Dari hasil wawancara secara umum dapat diketahui layanan yang diberikan oleh pustakawan sudah seperti yang diharapkan, hanya pada kasus koleksi tertentu saja seperti layanan yang berhubungan dengan buku praktek musik layanan yang diberikan dirasa belum maksimal.

Kepuasan pemustaka merupakan target utama yang harus dicapai dalam layanan perpustakaan. Dari hasil wawancara para informan menganggap kelengkapan koleksi dan kenyamanan ruang sangat dibutuhkan agar mereka merasa betah dan senang berkunjung ke perpustakaan. Kendala mahasiswa dalam memanfaatkan koleksi selain kenyamanan ruang adalah koleksi berbahasa asing dan koleksi yang belum mencakup ke minat utama yang mereka tempuh. Selain itu kelancaran wifi juga sangat dibutuhkan dalam rangka kegiatan temu kembali informasi untuk menunjang pemanfaatan $O P A C$ Mobile maupun untuk mengakses repository institusi. Perpustakaan sebagai salah satu sumber belajar sangat erat kaitannya dengan proses perkuliahan yang diselenggarakan oleh perguruan tinggi. Dari hasil wawancara maupun dari KHS (Kartu Ha- sil Studi) diperoleh data bahwa semua informan memberikan jawaban yang hampir sama bahwa intensitas memanfaatkan koleksi perpustakaan dapat meningkatkan prestasi belajar mereka.

\section{Kesimpulan dan Saran}

Berdasarkan analisis yang telah dilakukan, maka kesimpulan yang dapat diperoleh adalah intensitas pemanfaatan koleksi perpustakaan dipengaruhi oleh motif-motif tertentu seperti tugas yang diberikan oleh dosen dan dalam rangka menyelesaikan tugas akhir. Ketika dalam situasi tersebut frekuensi kunjungan mahasiswa mengalami peningkatan. Dalam masa menyelesaikan tugas akhir mahasiswa bisa berkunjung ke perpustakaan 1-3 per minggu. Koleksi yang paling sering dimanfaatkan adalah buku-buku yang terkait dengan perkuliahan. Sedangkan koleksi terbitan berkala seperti jurnal ilmiah dan majalah belum maksimal dimanfaatkan. Koleksi yang dimanfaatkan oleh mahasiswa tidak hanya berupa koleksi tercetak, namun mereka sudah memanfaatkan pula layanan digital dengan mengakses repository institusi.

Prestasi belajar mahasiswa yang dicapai selain ditentukan oleh kemampuan mahasiswa itu sendiri juga ditentukan oleh seringnya mahasiswa memanfaatkan perpustakaan sebagai sumber informasi ilmiah. Intensitas pemanfaatan koleksi perpustakaan oleh mahasiswa Fakultas Seni Pertunjukan ISI Yogyakarta berpengaruh positif terhadap prestasi akademik mahasiswa. Prestasi akademik dibuktikan dengan peningkatan nilai kumulatif.

Dimana adanya proses belajar mengajar yang optimal harus pula ditunjang oleh sarana dan prasarana pusat sumber informasi. Ruangan yang kurang nyaman, wifi yang tidak stabil, koleksi berbahasa asing dan kurang lengkapnya koleksi yang spesifik menurut kebutuhan minat utama menjadi kendala mahasiswa dalam memanfaatkan koleksi perpustakaan.

\section{Saran}

Berdasarkan temuan-temuan dalam penelitian, diajukan saran sebagai berikut: 


\section{Bagi Institusi}

Perlu adanya kerjasama yang baik antara pihak Fakultas Seni Pertunjukan ISI Yogyakarta dengan UPT Perpustakaan ISI Yogyakarta dalam rangka untuk meningkatkan pemanfaatan koleksi perpustakaan sehingga tumbuh minat baca yang tinggi yang akan meningkatkan prestasi belajar mahasiswa. Dosen-dosen disarankan memotivasi mahasiswa untuk memanfaatkan koleksi perpustakaan dengan memberikan tugas pengembangan materi kuliah dan tugas mandiri.

2. Bagi Mahasiswa

Intensitas pemanfaatan koleksi perpustakaan akan mempengaruhi tingkat pemahaman mahasiswa, dimana semakin sering memanfaatkan sumber informasi belajar akan meningkatkan pengetahuan yang secara tidak langsung akan berpengaruh terhadap prestasi belajar. Mengingat hal tersebut hendaknya para mahasiswa lebih memanfaatkan perpustakaan sebagai sumber informasi untuk menyelesaikan tugas-tugas kuliah sehingga prestasi belajar pun akan meningkat.

3. Bagi Perpustakaan

Perpustakaan perlu menyediakan ruangan yang nyaman mengingat mahasiswa memanfaatkan koleksi perpustakaan terbesar dengan cara membaca di tempat. Selain itu juga memperlancar akses internet di tiap ruang layanan agar mahasiswa memperoleh kenyamanan dan keleluasaan dalam memanfaatkan koleksi perpustakaan sebagai sumber belajar, mengingat saat ini perpustakaan juga menyediakan layanan digital. Perpustakaan hendaknya juga menyediakan koleksi yang disesuaikan hingga ke materi-materi minat utama dalam tiap-tiap program studi.

\section{Kepustakaan}

Agustiawan. 2019. "Menuju Perpustakaan Digital, Sebuah Refleksi UPT Perpustakaan ISI Yogyakarta" dalam Seni \& Revolusi Industri 4.0 ISI Yogyakarta Dalam Pusaran Virtual.
Yogyakarta: BP ISI Yogyakarta.

Anusapati. 2019. "Pelayanan Bidang Kemahasiswaan ISI Yogyakarta" dalam Seni \& Revolusi Industri 4.0: ISI Yogyakarta Dalam Pusaran Virtual. Yogyakarta: ISI Yogyakarta.

Budiningsih, Asri. 2015. Belajar \& Pembelajaran. Jakarta: Rineka Cipta.

Cresswell, John W. 2016. Research Design Edisi Keempat. Yogyakarta: Pustaka Pelajar.

Istiana, Purwani. 2014. Layanan Perpustakaan. Yogyakarta: Penerbit Ombak.

Lasa HS. 2009. Kamus Kepustakawanan Indonesia. Yogyakarta: Pustaka Book Publisher.

Moleong, Lexy J. 2006. Metode Penelitian Kualitatif Edisi revisi. Bandung: Remaja Rosdakarya.

Sulistiyo-Basuki. 2013. Pengantar Ilmu Perpustakaan. Tangerang Selatan. Universitas Terbuka.

Suryabrata, Sumadi. 2008. Psikologi Pendidikan. Jakarta: Raja Grafindo Persada.

Yusuf, A. Muri. 2015. Metode Penelitian Kuantitatif, Kualitatif \& Penelitian Gabungan. Jakarta: Prenada Media.

\section{Jurnal}

Handayani, Keni Hasti dan Nurdin Laugu. 2007. Studi Korelasi Motivasi Pengguna Dengan Pemanfaatan Koleksi CD-ROM di UPT Perpustakaan UII Yogyakarta. Dalam Jurnal Berkala Ilmu Perpustakaan \& Informasi Vol. III No. 7.

\section{Undang-undang dan Peraturan}

Institut Seni Indonesia Yogyakarta. 2020. Peraturan Institut Seni Indonesia Nomor 1 Tahun 2020 tentang Tata Tertib Pengguna Jasa Perpustakaan Institut Seni Indonesia Yogyakarta.

Indonesia. 2003 Undang-Undang No. 20 Tahun 2003 tentang Sistem Pendidikan Nasional.

Indonesia. 2007. Undang-Undang No. 43 Tahun 2007 tentang Perpustakaan. 